Illinois State University

ISU ReD: Research and eData

Theses and Dissertations

3-25-2019

\title{
Body Mass As The Optimal Load Predictor For Power Clean Variations: A Practical Approach
}

Marcel Lopes dos Santos

Illinois State University, marcel.unicamp@hotmail.com

Follow this and additional works at: https://ir.library.illinoisstate.edu/etd

Part of the Kinesiology Commons

\section{Recommended Citation}

Lopes dos Santos, Marcel, "Body Mass As The Optimal Load Predictor For Power Clean Variations: A Practical Approach" (2019). Theses and Dissertations. 1072.

https://ir.library.illinoisstate.edu/etd/1072

This Thesis is brought to you for free and open access by ISU ReD: Research and eData. It has been accepted for inclusion in Theses and Dissertations by an authorized administrator of ISU ReD: Research and eData. For more information, please contact ISUReD@ilstu.edu. 


\title{
BODY MASS AS THE OPTIMAL LOAD PREDICTOR FOR POWER CLEAN
}

\author{
VARIATIONS: A PRACTICAL APPROACH
}

\section{MARCEL LOPES DOS SANTOS}

\section{Pages}

The purpose of this study was to identify the optimal load of the Hang Power Clean (HPC), Hang High Pull (HHP), and Mid-thigh Clean Pull (MTP) based on a relative percentage of the subjects' body mass (BM). Fifteen males with experience in weightlifting (age: $21.8 \pm 1.9$ years; BM: $83.2 \pm 9.0 \mathrm{~kg}$; height: $175.4 \pm 6.0 \mathrm{~cm}$; 1-repetition maximum [1RM]: $93.0 \pm 12.7 \mathrm{~kg}$; 1RM to BM ratio: $1.12 \pm 0.13$ ) performed HPC, HHP, and MTP at intensities of 30, 40, 50, 60, 70, 80, and 90\% BM. Kinematic data were collected through a 16-camera infrared motion capture system and processed based on a three-dimensional lower-extremity model. Kinetic data were collected from two force plates. Peak power was found at 80, 80, and 90\% BM for HPC, HHP, and MTP, respectively. Highest peak power output was found during the HHP for all intensities when compared to HPC and MTP. Power production was higher in the MTP from 30$70 \%$ BM when compared to HPC, but at 80-90\% BM this shifted toward HPC prevalence over MTP. Results of the present study indicate that relative percentages of body mass presented as a reliable alternative for prescribing loads for the HPC, HHP, and MTP for healthy males with experience in resistance training. This information is relevant for load prescription for exercises without the catch phase (HHP, MTP) in which trainers and coaches rely on 1RM tests in exercises with more technical complexity such as the power clean (PC) and HPC. 
KEYWORDS: weightlifting derivatives, hang power clean, hang high pull, olympic weightlifting, mid-thigh clean pull, power training 
BODY MASS AS THE OPTIMAL LOAD PREDICTOR FOR POWER CLEAN

VARIATIONS: A PRACTICAL APPROACH

MARCEL LOPES DOS SANTOS

A Thesis Submitted in Partial

Fulfillment of the Requirements

for the Degree of

\section{MASTER OF SCIENCE}

School of Kinesiology and Recreation

ILLINOIS STATE UNIVERSITY

2019 
(C) 2019 Marcel Lopes dos Santos 
BODY MASS AS THE OPTIMAL LOAD PREDICTOR FOR POWER CLEAN

VARIATIONS: A PRACTICAL APPROACH

MARCEL LOPES DOS SANTOS

COMMITTEE MEMBERS:

Kristen M. Lagally, Chair

Adam E. Jagodinsky

Michael Torry 


\section{ACKNOWLEDGMENTS}

First and foremost, I would like to thank God for giving me health, strength, confidence, and stubbornness to remain faithful to my convictions. I would also like to thank my family who gave me unconditional support throughout the graduate school process, even from 5,115 miles away and all the people around me who encouraged me to persevere in my ultimate goal. I would like to thank Dr. Lagally not only for her readiness and support in every single step of the project but mostly for purchasing the idea and guiding me. I would like to thank Dr. Torry for opening the doors of the Biomechanics Lab and allowing me to use the facility and Dr. Jagodinsky for his patience and for the very productive meetings in which we discussed and covered every aspect of the project, including data collection, processing, interpretation, and practical applications.

Lastly, I would like to give my deepest thanks to every single one of my subjects who participated in this study. This project would not be achievable without their valuable contribution.

M.L.S. 


\section{CONTENTS}

Page

ACKNOWLEDGMENTS

CHAPTER I: BODY MASS AS THE OPTIMAL LOAD PREDICTOR FOR POWER CLEAN VARIATIONS: A PRACTICAL APPROACH 1

Introduction $\quad 1$

$\begin{array}{ll}\text { Methods } & 4\end{array}$

Experimental Approach to the Problem 4

$\begin{array}{ll}\text { Subjects } & 4\end{array}$

Procedures $\quad 5$

1-Repetition Maximum Hang Power Clean Protocol 5

Hang Power Clean 6

$\begin{array}{ll}\text { Hang High Pull } & 7\end{array}$

$\begin{array}{ll}\text { Mid-thigh Pull } & 7\end{array}$

$\begin{array}{ll}\text { Power Assessment } & 7\end{array}$

$\begin{array}{ll}\text { Statistical Analysis } & 9\end{array}$

Results 9

Overall Peak Power 9

$\begin{array}{ll}\text { Discussion } & 10\end{array}$

$\begin{array}{ll}\text { Hang Power Clean } & 10\end{array}$

$\begin{array}{ll}\text { Hang High Pull } & 10\end{array}$

$\begin{array}{ll}\text { Mid-thigh Clean Pull } & 11\end{array}$

Optimal Load based on BM in Different Weightlifting Derivatives 12 
Practical Applications

Acknowledgments

REFERENCES 


\section{CHAPTER I: BODY MASS AS THE OPTIMAL LOAD PREDICTOR FOR POWER CLEAN}

\section{VARIATIONS: A PRACTICAL APPROACH}

\section{Introduction}

Several factors contribute to success in sports. In addition to technical and tactical aspects, physical fitness can be considered a key factor during training. Athletes' success in a wide range of sports is intimately linked to their capacity for producing muscular power effectively $(11,14)$. Effective muscular power production is essential to performance, especially in sports modalities that involve sprints, jumping, and change of directions $(3,14,15,26)$. Hence, specific training strategies that address the enhancement of athletes' individual capacity to produce muscular power have become fundamental $(22,24)$.

Muscular power is resultant from muscular force and its contraction velocity. Both neural and muscular adaptations achieved through resistance training will contribute to an improvement in the muscular power production $(10,11,37)$. Nevertheless, the literature has shown that muscular power production enhancement is optimized when the activities included in the training program are similar to motions commonly performed in game situations $(4,9,11,37)$. Power output values are determined by the force applied during the motion, normally through global ground reaction force (GRF), and the velocity of the system (barbell + body) movement. Thus, power training strategies that target not only force but also the velocity component have become attractive $(1,2,12,14,37)$. Consequently, plyometric and weightlifting training have been introduced as major components in training programs because they work the same musculature utilized in sport-specific motions $(31,37)$ and result in more improvements in performance when compared to resistance training alone $(2,12,14,25,30)$. 
However, to maximize the power output in a specific motion it is expected that the athletes train at the intensity in which they elicit the peak power output, also known as the optimal load $(17,29)$. Optimal load identification requires a 1-repetition maximum (1RM) test and execution of the exercise at four to eight relative percentages of the 1RM to determine the intensity at which the peak power output occurs for that specific exercise. Although this is the best way to determine the optimal load, injuries may occur due to lifting very heavy loads during a complex move and an exceedingly amount of time is required to be exclusively dedicated for testing. 1RM testing commonly begins with a rest period of 24 hours that is followed by the $1 \mathrm{RM}$ test and another 48-72 hours of rest precedes a second 1RM test in which the value obtained during the first test will be confirmed. Moreover, following the two 1RM tests, four to eight relative percentages of the $1 \mathrm{RM}$ are tested on a lab setting to determine the percentage of 1RM that elicits the peak power output. This session is also preceded by a 24-hour rest period. This entire process may take up to ten days to complete. Furthermore, training loads must continually be adjusted due to athletes' neuromuscular adaptations to training, requiring additional testing time and compromising the number of actual training sessions of a program.

Weightlifting derivatives such as the Power Clean (PC), Hang Power Clean (HPC), Hang High Pull (HHP), Mid-thigh Clean Pull (MTP), and Jump Shrug (JS) emphasize different phases of the pull and/or throw and can promote a considerable increase in muscular power production levels and therefore improvements in sports performance $(11,14)$. However, the optimal load determination for these exercises in training programs is not a simple task. For weightlifting derivatives without the catch phase (i.e., JS, HHP, MTP), it is not possible to accurately assess the complete range of motion and therefore the $1 \mathrm{RM}$ test is not a viable option. Consequently, the strategy that has largely been used to determine the training load for these exercises is using 
percentages of the PC or HPC $(6,27,33)$. However, the application of this method requires the individual to become very proficient in a more complex exercise to determine the training load of less complex exercises $(5,20,34)$.

Given the disadvantages of performing 1RM tests to determine the optimal load, other methods such as body mass (BM) utilization as the main parameter presents as a viable option. Loturco et al., present a relation between BM and the intensity at which the optimal load is identified with ballistic and non-ballistic exercises. For instance, peak power outputs were found at $80 \%, 100 \%, 35 \%$, and $40 \% \mathrm{BM}$, for the jump squat, half squat, bench throw, and bench press, respectively (24).

Following preliminary analyzes in different publications, we observed that even in diverse athletic populations (e.g., different sports, genders, years of practice) results from body mass percentages can be extrapolated for weightlifting derivatives $(5,7-9,17,19,32,34)$. Notwithstanding, utilization of the BM as the parameter to determine the training load for weightlifting derivatives have not been tested yet and it presents as a practical and safe alternative that could benefit both trainers and athletes. Using BM to determine the optimal load for each exercise would exclude the need for the athlete to learn a more technical exercise (PC or HPC) to determine the training load for simpler exercises (HHP, MTP, JS). Only one effortless assessment session in which the athlete's BM is measured would be required to identify the training load. More importantly, the athletes will be able to train at the respective training loads for each exercise regardless of their proficiency in the PC or HPC. Therefore, the aim of this study was to identify the optimal load of weightlifting derivatives (HPC, HHP, and MTP) based on a relative percentage of the total $\mathrm{BM}$. 


\section{Methods}

\section{Experimental Approach to the Problem}

This study used a repeated measures design to assess power output at several submaximal intensities based on percentages of body mass. Subjects participated in four separate sessions. In the first session subjects performed a 1RM for the HPC and were familiarized with HHP and MTP. During the second, third, and fourth sessions the subjects performed the HPC, HHP, and MTP at weights equivalent to $30,40,50,60,70,80$, and $90 \%$ of their BM in order to determine the percentage at which peak power output was achieved. Testing occurred in different days but on the same time of the day, with at least 48 hours between sessions. Testing sessions occurred at least 48 hours after the 1RM HPC.

\section{Subjects}

Fifteen healthy males familiar with weightlifting derivatives participated in this study. All subjects were engaged in resistance training for more than 2 years and were proficient in PC and/or HPC. Subjects' descriptive characteristics are listed in Table 1. Subjects were asked to refrain from strenuous exercise, alcohol and caffeine at least 24 hours before the testing sessions. This study was approved by the Illinois State University Institutional Review Board. Before participation, subjects' medical history was assessed, they were informed of the possible risks of the study, provided written informed consent, and had all questions related to the study answered. 


\section{Procedures}

Subjects participated in four testing sessions. Testing sessions occurred on different days over the period of three weeks with at least 48 hours between each testing session. A standard dynamic warm-up preceded each session and consisted of five minutes of light jogging on the treadmill followed by stretching, and two sets of a few repetitions of the exercise that was being performed that day (HPC, HHP or MTP). One set was performed with the bar only and the other with $50 \%$ of their BM. In session one, subjects completed a 1RM for the HPC and were familiarized with HHP and MTP. In sessions two, three, and four subjects performed 3 repetitions of HPC, HHP or MTP at seven intensities (30, 40, 50, 60, 70, 80, and 90\% BM). Both exercise order and intensities were randomized to minimize biased responses.

\section{1-Repetition Maximum Hang Power Clean Protocol}

Subjects were asked to estimate their HPC 1RM and that load was used as their first try during the testing. If the subjects were not sure about their estimated 1RM HPC, the initial load was equal to their total BM. Subjects were asked to refrain from strenuous exercise for at least 24 hours prior to the test. The 1RM test was preceded by a standard dynamic warm-up protocol in which the subjects jogged for 5 minutes on a treadmill, stretched, and performed HPCs without any plates on the barbell until self-reported ready. After that, subjects were asked to execute 8 HPC repetitions at 50\% BM followed by $3 \mathrm{HPC}$ repetitions at $70 \% \mathrm{BM}$ with 2 minutes and 30 seconds of rest between trials. The first load for all subjects was set at $100 \%$ of their BM. Following that, two to five kg were added or removed after each trial until a true 1RM HPC was found. Failed attempts were followed by a second attempt with the same load. In case of a second failed attempt, the highest successful attempt was considered as the subjects' 1RM HPC. 
A rest period of at least 2 minutes and 30 seconds was provided between all trials. A trial was considered successful if the HPC execution was in agreement with the National Strength and Conditioning Association (NSCA) guidelines (28) and unsuccessful if the subject's thigh went below parallel to the floor during the catch phase. After the 1RM HPC was established, each subject was familiarized with the HHP and MTP techniques.

\section{Hang Power Clean}

The HPC began with the barbell and weight resting on two weightlifting boxes and the subjects standing with shins making contact with the middle of the bar (Figure 1). Subjects were standing on two force plates with each foot on a force plate. Subjects were instructed to maintain a flat back and pull their shoulder blades together while squatting down and grasping the bar with a pronated grip slightly wider than shoulder-width and straight arms with elbows pointed out. Then, the subjects were instructed to slowly extend the knees to elevate the bar to just above the knees and, as the bar passed the knees, to extend their hips. At this point the subjects were in the starting position. The HPC procedure began with the subjects lowering the bar to the top of their knees by flexing their hips. With shoulders in front of the bar, back flat, arms extended with elbows pointed out, and knees slightly bent, they explosively extended their hips, knees, and ankles in order to accelerate the barbell upward while quickly pulling their body under the bar. Then, subjects flexed their hips backward, sat in a quarter squat position to absorb the weight of the bar, and rotated the elbows down and up ahead to catch the bar on the front portion of the shoulders. Finally, the subjects stood erect with feet flat on the force plates. A trial was considered unsuccessful if the subjects had their hips and upper thighs going below parallel to the floor $\left(90^{\circ}\right)$. 


\section{Hang High Pull}

The starting position for the HHP followed the HPC procedures described above. With the bar right above their knees, the subjects extended onto the balls of their feet and shrugged shoulders straight up, pulling the bar upward to neck height while keeping the bar close to the body with arms straight and elbows pointed out until the body was fully extended (Figure 2). Then, they went back to the starting position by lowering the bar slowly with the elbows slightly flexed.

\section{Mid-thigh Pull}

Starting position for the MTP also followed the HPC procedures described above. However, instead of having the bar resting right above their knees, subjects had the bar in between knees and hips, at mid-thigh height (Figure 3). During the upward phase, they explosively performed a triple extension in order to accelerate the bar while shrugging their shoulders with elbows straight and bar close to the body.

\section{Power Assessment}

During power assessment, subjects performed three repetitions at seven intensities (30\% through $90 \%$ of BM) in random order. The bar was resting on two wood blocks adjusted to each subjects' knee height and, after performance of the three repetitions at a given intensity, a rest period of at least 2 minutes and 30 seconds was provided to prevent fatigue. Subjects were asked to return the bar to the starting position after each repetition and to avoid countermovement before starting the movement. In case of a failed attempt, additional trials with the same load were performed following the same rest period and the highest value obtained during the three 
repetitions was considered the peak power output for each intensity of each exercise. Only the concentric phase of the pull for each repetition of each exercise was analyzed. Power output was measured based on a combination of kinetic: ground reaction force (GRF)-time data and kinematic: center of mass velocity $(\mathrm{COMv})$ of the system (barbell + body). It has been reported that this combination in addition to a proper biomechanical modeling is required for accurate measures of power in human motions (21).

Kinematic data were collected during all repetitions of all trials and processed based on a three-dimensional lower-extremity model with Visual 3D biomechanics software (C-Motion Inc, Germantown, Maryland, USA). A Vicon 16-camera infrared motion capture system (ViconMX, Los Angeles, California, USA) sampling at $200 \mathrm{~Hz}$ captured the movement based on reflective markers placed on the lower body of the subjects. A total of 33 reflective markers were placed on subjects for kinematic data calculation. Markers were attached to anterior superior iliac spines of the pelvis $(2 \mathrm{x})$, sacrum $(1 \mathrm{x})$, trochanters of the femur $(2 \mathrm{x})$, lateral mid-thighs $(8 \mathrm{x})$, medial and lateral epicondyles of the knees $(4 x)$, lateral shanks $(6 x)$ medial and lateral malleoli of the ankles $(4 \mathrm{x}), 2^{\text {nd }}$ and $5^{\text {th }}$ metatarsals $(4 \mathrm{x})$, and heels $(2 \mathrm{x})$ (Figure 4$)$. Reflective markers were attached with double-sided tape and secured with extra tape as necessary. Data collection started with a static trial in which the subjects stood in an anatomically neutral position. Kinetic data were collected from two force plates (Advanced Mechanical Technology Inc, Watertown, MA, USA) sampling at $1000 \mathrm{~Hz}$. Subjects were asked to keep each foot on a single force plate throughout every trial. Results from each force plate were summed to form the GRF value and data were resampled to $200 \mathrm{~Hz}$ to match the kinematic sampling. Reflective markers, kinematic and GRF data were lowpass filtered at $6 \mathrm{~Hz}$ in Visual 3D. 


\section{Statistical Analysis}

Normality of the data was assessed by Shapiro-Wilk's test. A repeated measures one-way ANOVA was used to examine significant differences in power (W) during the HPC, HHP, and MTP. Follow-up analysis included Bonferroni post hoc comparisons. A two-way ANOVA with Bonferroni's post hoc multiple comparisons test was used to assess interaction effects for load by exercise. Data were reported as mean \pm standard deviation (SD) and statistical significance level was set at $\mathrm{p} \leq 0.05$. All statistics were performed using IBM SPSS 23 (IBM, New York, NY, USA) and GraphPad Prism 7.01 (GraphPad Software, La Jolla, California, USA). In addition, multi-variate (partial $\eta 2$ ) effect sizes and statistical power (power) are presented.

\section{Results}

\section{Overall Peak Power}

HPC peak power occurred at $80 \% \mathrm{BM}$ and it was significantly different than $60,50,40$, and $30 \% \mathrm{BM}(\mathrm{p}=0.0006)$ whereas not statistically different than 70 and $90 \%$ BM. HHP peak power occurred at $80 \% \mathrm{BM}$ and it was statistically different than $30 \% \mathrm{BM}(\mathrm{p}=0.002)$ whereas not statistically different than 90, 70, 60, 50, and 40\% BM. MTP peak power occurred at $90 \%$ $\mathrm{BM}$ and it was not statistically different than $80,70,60,50,40$, and $30 \% \mathrm{BM}$ whereas 70 and $60 \%$ were statistically different than $30 \%$ BM $(\mathrm{p}=0.04)$. Results for HPC, HHP and MTP are displayed in Table 2 and Figure 6. Statistical results for the 2-way ANOVA indicated a significant interaction effect for load by exercise $(F(12,266)=14.26, p=0.0001)$. Estimated effect sizes of $\eta 2=0.965,0.934$, and 0.942 at observed power levels of 1.000, 1.000, and 1.000 were found for peak power during HPC, HHP, and MTP, respectively. Results for HPC, HHP, and MTP comparisons are displayed in Figure 5. 


\section{Discussion}

This study aimed to identify the optimal load for three weightlifting derivatives (HPC, HHP, and MTP) based on one's body mass. Peak power values were found at $80 \%, 80 \%$, and 90\% BM for the HPC, HHP, and MTP, respectively.

\section{Hang Power Clean}

Several studies have investigated the optimal training load for the HPC. HPC peak power has widely been reported to be at $65-80 \% 1 \mathrm{RM} \operatorname{HPC}(17,19,32,34,35)$ with very little variation among studies, and in most cases with no statistical difference to intensities near the highest obtained value. It should be noted that when converting the same values to percentages of the subjects' body mass in each of these previous studies, the values are in line with the ones found in the present study (80\% of BM). For example, Kawamori et al. (16), Suchomel et al. $(34,35)$, Kilduff et al. (19), and Kipp et al. (20), have reported HPC peak power at 70, 65, 80, and 70\% 1RM HPC, or approximate values of $83,82,84$, and 87\% BM, respectively. This consistency among studies indicates that BM might be a useful tool in training load prescription as long as the subjects have proficiency in the HPC.

\section{Hang High Pull}

Although peak power for the HHP was found at $80 \%$ BM, it was only statistically different than $30 \% \mathrm{BM}$ and therefore it can be assumed that optimal load for HHP was found at 40-90\% BM. This results are in line with Thomas et al. (36) who reported no statistical difference in HHP peak power across 30-60\% 1RM for both genders. In another study, 
Suchomel et al. (33), found a peak power output for the HHP during 45\% 1RM HPC, although it was not statistically different than 30\% 1RM. Since there was no significant difference from 40$90 \% \mathrm{BM}$ in the present study, it can be assumed that subjects produced similar mechanical power despite the increase in load. In other words, the lack of difference in mechanical power across loads higher than $40 \% \mathrm{BM}$ for the HHP suggests that training at a low to moderate intensity may be enough to provide proper stimuli to enhance one's power performance. Although the optimal load for the HHP encompasses a wide range of intensities, overall mechanical power is influenced by fluctuations in force and velocity. Peak force in the HHP has been suggested to be achieved at $80 \% 1 \mathrm{RM}$ HPC whereas peak velocity is achieved at $30 \% 1 \mathrm{RM}$ HPC (33). From a training perspective, this can be critical when prescribing the HHP, especially when it comes to the transferability of training outcomes to sport-specific motions (e.g., sprinting, jumping, throwing, etc).

\section{Mid-thigh Clean Pull}

MTP peak power was found at the heaviest load tested in this study (90\% BM). However, it was not statistically different than any of the other intensities. MTP peak power reported in this study is in line with the one reported by Kawamori et al. (18). In their study, MTP peak power was obtained at $60 \%$ 1RM PC ( 84\% BM) but not statistically different than 30,90 , and $120 \%$ 1RM PC. However, they presented a positive correlation between the peak force at $90 \%$ MTP and peak force, peak power, and peak rate of force development during the static vertical jump. This shows the importance of the force component in power training for that specific motion. Therefore, training at higher intensities during the MTP might be more efficient for that particular movement. Our results are also in line with Haff et al. (13), who reported a peak power 
at $80 \%$ 1RM PC ( 96\% BM) for the MTP, however only intensities 80,90 , and 100\% 1RM PC were tested. There is a possibility that higher values for power would have been found if additional lighter intensities were tested. Ultimately, there is value in comparing the outcomes of these studies with the ones reported in this study but comparison with these studies should be made with caution. Other studies have suggested that the optimal power for the MTP occurs at 40-60\% 1RM PC $(5,6)$, but these studies used the 1RM PC as the reference to determine the percentages in which the MTP would be tested, and we should be careful when interpreting the outcomes, as stated by Kawamori et al. (18). A more effective alternative would be determining the 1RM MTP prior to determine a relative percentage at which the peak power output for that exercise occurs.

\section{Optimal Load based on BM in Different Weightlifting Derivatives}

Although body mass has previously been suggested as a possible practical strategy to prescribe training load for weightlifting derivatives $(9,33)$, to the authors knowledge, this is the first study that investigated relative percentages of the subjects' body mass as the parameter to determine the optimal load. Another unique aspect of this study is the comparison of the peak power among three different exercises that emphasize the same aspects of the lift during the second pull in the concentric phase with rapid and explosive triple extension of the lower-body joints and use of similar musculature. Peak power outputs for the three exercises differ significantly from each other in the majority of the intensities (Figure 5). Highest peak power output was found during the HHP for all intensities when compared to HPC and MTP. Interestingly, power production was higher in the MTP from 30-70\% BM when compared to HPC, but at 80-90\% BM this shifted toward HPC prevalence over MTP. As stated before, there 
are several factors such as rate of force development (6), impulse (6,23), propulsion (34) and joint internal power output (20) that contribute to effective levels of power production. That reinforces the idea of prescribing not only the exercises that work the same musculature/joints but also the ones that are more similar in nature with sport-specific moves, so the athlete can enhance performance more effectively. Although subjects in this study were proficient in HPC, they were only required to have at least 2 years of experience in resistance training. We believe that in more homogeneous groups this relationship will be even stronger due to the longevity of training and similarities in training routines.

\section{Practical Applications}

The results of the present study indicate that relative percentages of body mass presented as a reliable alternative for load prescription for the HPC, HHP, and MTP for healthy males with experience in resistance training. This information is relevant for load prescription for exercises without the catch phase (HHP, MTP) in which trainers and coaches rely on 1RM tests in exercises with more technical complexity such as PC and HPC. HHP and MTP have specific characteristics and training at each athlete's respective optimal loads can be prescribed not only for overall enhancement of power but for improvement of variables that contribute to an effective power output such as impulse, rate of force development, and propulsion. Moreover, using a relative percentage of $\mathrm{BM}$ to determine the training load excludes the need for mastering complex lifts in situations in which HHP and MTP are the best option. Using relative percentages of BM is also less time-consuming and potential risks of injury in lifting heavy loads during complex exercises can be avoided. Such a strategy can be used in groups of athletes for which 1RM tests are not the most viable option. 


\section{Acknowledgments}

There are no professional relationships with companies or manufacturers who will benefit from the results of the present study for each author. The results of the present study do not constitute endorsement of the product by the authors or the NSCA. There are no conflicts of interest. 


\section{REFERENCES}

1. Aagaard, P, Simonsen, EB, Trolle, M, Bangsbo, J, and Klausen, K. Effects of different strength training regimes on moment and power generation during dynamic knee extensions. Eur J Appl Physiol Occup Physiol 69: 382-386, 1994.

2. Adams, K, O'Shea, JP, O'Shea, KL, and Climstein, M. The Effect of Six Weeks of Squat, Plyometric and Squat-Plyometric Training on Power Production. The Journal of Strength \& Conditioning Research 6, 1992.Available from: https://journals.lww.com/nscajscr/Fulltext/1992/02000/The_Effect_of_Six_Weeks_of_Squat,_Plyometric_and.6.aspx

3. Barker, M, Wyatt, TJ, Johnson, RL, Stone, MH, O’Bryant, HS, Poe, C, et al. Performance Factors, Psychological Assessment, Physical Characteristics, and Football Playing Ability. The Journal of Strength \& Conditioning Research 7, 1993.Available from: https://journals.lww.com/nscajscr/Fulltext/1993/11000/Performance_Factors,_Psychological_Assessment,.7.aspx

4. Behm, DG, Young, JD, Whitten, JHD, Reid, JC, Quigley, PJ, Low, J, et al. Effectiveness of Traditional Strength vs. Power Training on Muscle Strength, Power and Speed with Youth: A Systematic Review and Meta-Analysis. Frontiers in Physiology 8, 2017.Available from: http://journal.frontiersin.org/article/10.3389/fphys.2017.00423/full

5. Comfort, P, Jones, PA, and Udall, R. The effect of load and sex on kinematic and kinetic variables during the mid-thigh clean pull. Sports Biomech 14: 139-156, 2015.

6. Comfort, P, Udall, R, and Jones, PA. The effect of loading on kinematic and kinetic variables during the midthigh clean pull. J Strength Cond Res 26: 1208-1214, 2012.

7. Cormie, P, McBride, JM, and McCaulley, GO. Validation of power measurement techniques in dynamic lower body resistance exercises. J Appl Biomech 23: 103-118, 2007. 
8. Cormie, P, McBride, JM, and McCaulley, GO. The influence of body mass on calculation of power during lower-body resistance exercises. J Strength Cond Res 21: 1042-1049, 2007.

9. Cormie, P, McCaulley, GO, Triplett, NT, and McBride, JM. Optimal loading for maximal power output during lower-body resistance exercises. Med Sci Sports Exerc 39: 340-349, 2007.

10. Cormie, P, McGuigan, MR, and Newton, RU. Developing Maximal Neuromuscular Power: Part 1 - Biological Basis of Maximal Power Production. Sports Medicine 41: 17-38, 2011.

11. Cormie, P, McGuigan, MR, and Newton, RU. Developing Maximal Neuromuscular Power: Part 2 - Training Considerations for Improving Maximal Power Production. Sports Medicine 41: 125-146, 2011.

12. Ebben, WP. Complex training: a brief review. J Sports Sci Med 1: 42-46, 2002.

13. Haff, GG, Stone, M, O’Bryant, HS, Harman, E, Dinan, C, Johnson, R, et al. Force-Time Dependent Characteristics of Dynamic and Isometric Muscle Actions. The Journal of Strength \& Conditioning Research 11, 1997.Available from: https://journals.lww.com/nscajscr/Fulltext/1997/11000/Force_Time_Dependent_Characteristics_of_Dynamic.14.aspx

14. Haff, GG and Stone, MH. Methods of Developing Power With Special Reference to Football Players: Strength and Conditioning Journal 37: 2-16, 2015.

15. Hori, N, Newton, RU, Andrews, WA, Kawamori, N, McGuigan, MR, and Nosaka, K. Does performance of hang power clean differentiate performance of jumping, sprinting, and changing of direction? J Strength Cond Res 22: 412-418, 2008. 
16. Kawamori, N, Crum, AJ, Blumert, PA, Kulik, JR, Childers, JT, Wood, JA, et al. Influence of Different Relative Intensities on Power Output During the Hang Power Clean: Identification of the Optimal Load. The Journal of Strength and Conditioning Research 19: 698, 2005.

17. Kawamori, N and Haff, GG. The optimal training load for the development of muscular power. J Strength Cond Res 18: 675-684, 2004.

18. Kawamori, N, Rossi, SJ, Justice, BD, Haff, EE, Pistilli, EE, O’Bryant, HS, et al. Peak force and rate of force development during isometric and dynamic mid-thigh clean pulls performed at various intensities. J Strength Cond Res 20: 483-491, 2006.

19. Kilduff, LP, Bevan, H, Owen, N, Kingsley, MIC, Bunce, P, Bennett, M, et al. Optimal loading for peak power output during the hang power clean in professional rugby players. Int J Sports Physiol Perform 2: 260-269, 2007.

20. Kipp, K, Malloy, PJ, Smith, JC, Giordanelli, MD, Kiely, MT, Geiser, CF, et al. Mechanical Demands of the Hang Power Clean and Jump Shrug: A Joint-Level Perspective. J Strength Cond Res 32: 466-474, 2018.

21. Knudson, DV. Correcting the Use of the Term "Power" in the Strength and Conditioning Literature: Journal of Strength and Conditioning Research 23: 1902-1908, 2009.

22. Kobal, R, Loturco, I, Barroso, R, Gil, S, Cuniyochi, R, Ugrinowitsch, C, et al. Effects of Different Combinations of Strength, Power, and Plyometric Training on the Physical Performance of Elite Young Soccer Players: Journal of Strength and Conditioning Research 31: 1468-1476, 2017. 
23. Lake, J, Lauder, M, Smith, N, and Shorter, K. A comparison of ballistic and nonballistic lower-body resistance exercise and the methods used to identify their positive lifting phases. J Appl Biomech 28: 431-437, 2012.

24. Loturco, I, Pereira, LA, Abad, CCC, Tabares, F, Moraes, JE, Kobal, R, et al. Bar velocities capable of optimising the muscle power in strength-power exercises. Journal of Sports Sciences 35: 734-741, 2017.

25. Mihalik, JP, Libby, JJ, Battaglini, CL, and McMurray, RG. Comparing Short-Term Complex and Compound Training Programs on Vertical Jump Height and Power Output: Journal of Strength and Conditioning Research 22: 47-53, 2008.

26. Nimphius, S, Mcguigan, MR, and Newton, RU. Relationship Between Strength, Power, Speed, and Change of Direction Performance of Female Softball Players: Journal of Strength and Conditioning Research 24: 885-895, 2010.

27. Oranchuk, DJ, Robinson, TL, Switaj, ZJ, and Drinkwater, EJ. Comparison of the Hang High-Pull and Loaded Jump Squat for the Development of Vertical Jump and Isometric Force-Time Characteristics. J Strength Cond Res , 2017.

28. Sands, WA, Wurth, JJ, and Hewit, JK. Basics of strength and conditioning manual.

29. Soriano, MA, Suchomel, TJ, and Marín, PJ. The Optimal Load for Maximal Power Production During Upper-Body Resistance Exercises: A Meta-Analysis. Sports Med 47: 757-768, 2017.

30. Stasinaki, A-N, Gloumis, G, Spengos, K, Blazevich, AJ, Zaras, N, Georgiadis, G, et al. Muscle Strength, Power, and Morphologic Adaptations After 6 Weeks of Compound vs. Complex Training in Healthy Men: Journal of Strength and Conditioning Research 29: 2559-2569, 2015. 
31. Stone, MH, O’Bryant, HS, McCoy, L, Coglianese, R, Lehmkuhl, M, and Schilling, B. Power and maximum strength relationships during performance of dynamic and static weighted jumps. J Strength Cond Res 17: 140-147, 2003.

32. Suchomel, TJ, Beckham, GK, and Wright, GA. The impact of load on lower body performance variables during the hang power clean. Sports Biomech 13: 87-95, 2014.

33. Suchomel, TJ, Beckham, GK, and Wright, GA. Effect of various loads on the force-time characteristics of the hang high pull. J Strength Cond Res 29: 1295-1301, 2015.

34. Suchomel, TJ and Sole, CJ. Power-Time Curve Comparison between Weightlifting Derivatives. J Sports Sci Med 16: 407-413, 2017.

35. Suchomel, TJ, Wright, GA, Kernozek, TW, and Kline, DE. Kinetic comparison of the power development between power clean variations. J Strength Cond Res 28: 350-360, 2014.

36. Thomas, GA, Kraemer, WJ, Spiering, BA, Volek, JS, Anderson, JM, and Maresh, CM. Maximal Power at Different Percentages of One Repetition Maximum: Influence of Resistance and Gender. The Journal of Strength and Conditioning Research 21: 336, 2007.

37. Vissing, K, Brink, M, Lønbro, S, Sørensen, H, Overgaard, K, Danborg, K, et al. Muscle Adaptations to Plyometric vs. Resistance Training in Untrained Young Men: Journal of Strength and Conditioning Research 22: 1799-1810, 2008. 


\section{APPENDIX: FIGURES AND TABLES}

\section{Figure Legends}

Figure 1. Hang Power Clean.

Figure 2. Hang High Pull.

Figure 3. Mid-thigh Clean Pull.

Figure 4. Reflective markers placement.

Figure 5. HPC, HHP, and MTP average peak power for all loads. * Significant difference between HPC and HHP ( $\mathrm{p} \leq 0.005) ; \uparrow$ Significant difference between HPC and MTP $(\mathrm{p} \leq 0.005)$; \# Significant difference between HHP and MTP $(\mathrm{p} \leq 0.005)$.

Figure 6. Hang Power Clean (A), Hang High Pull (B), and Mid-thigh Clean Pull (C) average peak power. $*$ Statistically different than $60,70,80$, and $90 \%(\mathrm{p} \leq 0.003) ; * *$ Statistically different than 80 and $90 \%(\mathrm{p} \leq 0.02)$; \# Statistically different than $30 \%(\mathrm{p} \leq 0.05)$. 


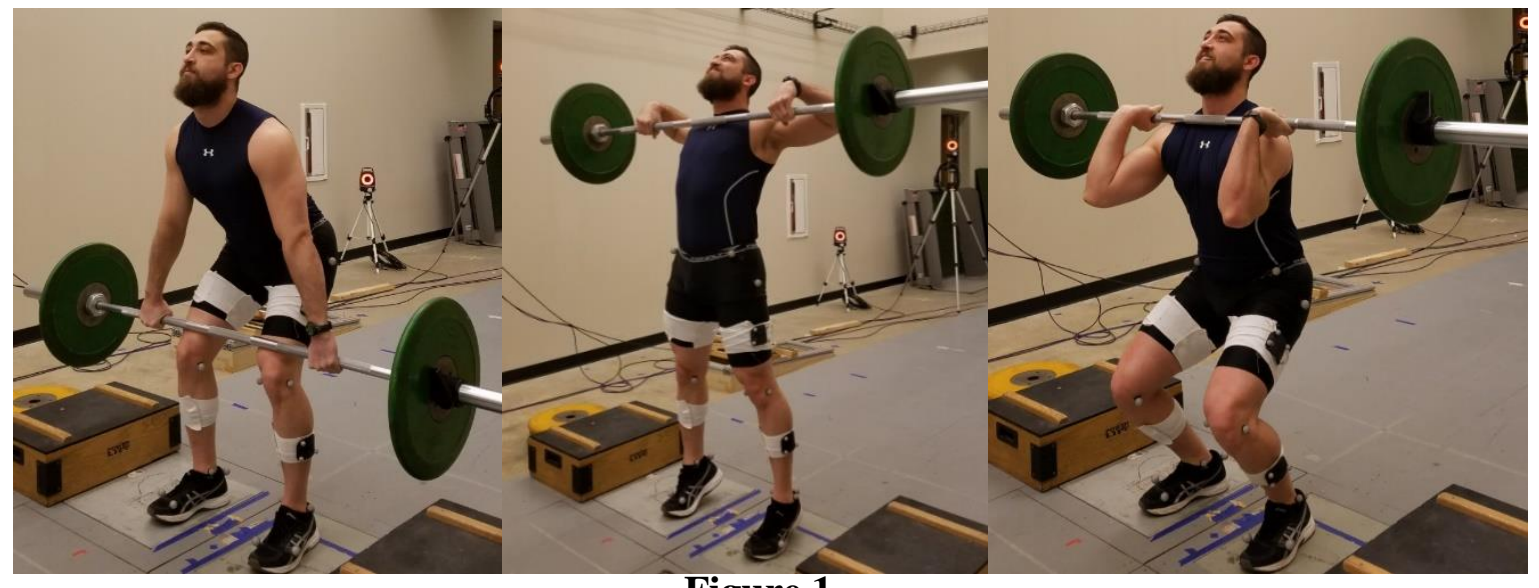

Figure 1 


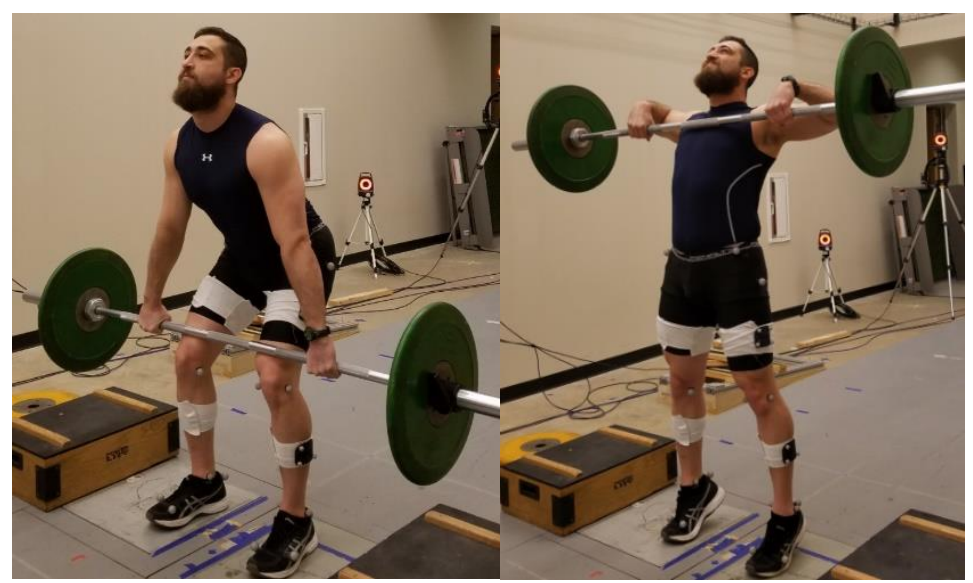

Figure 2 


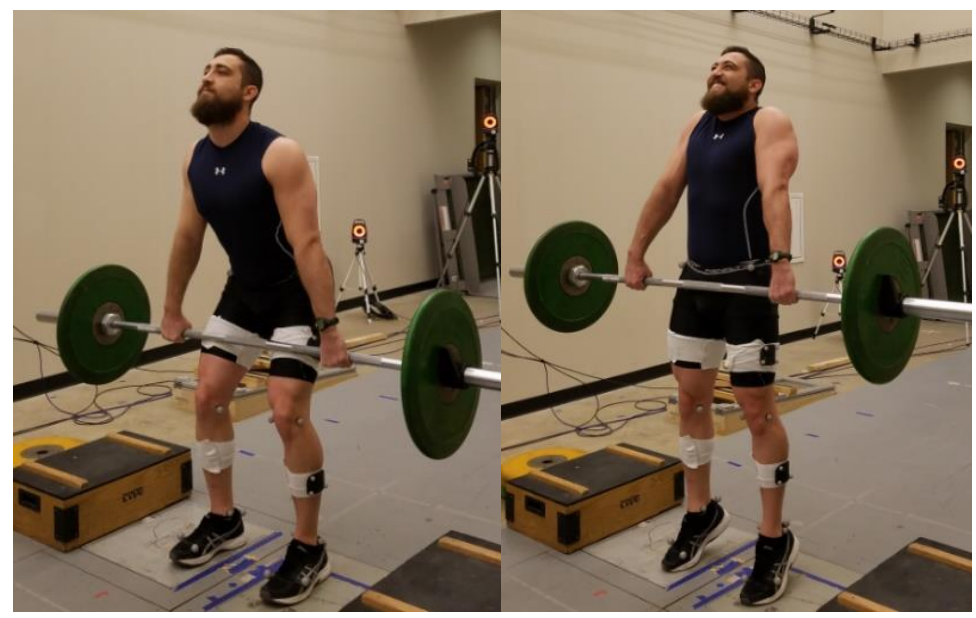

Figure 3 


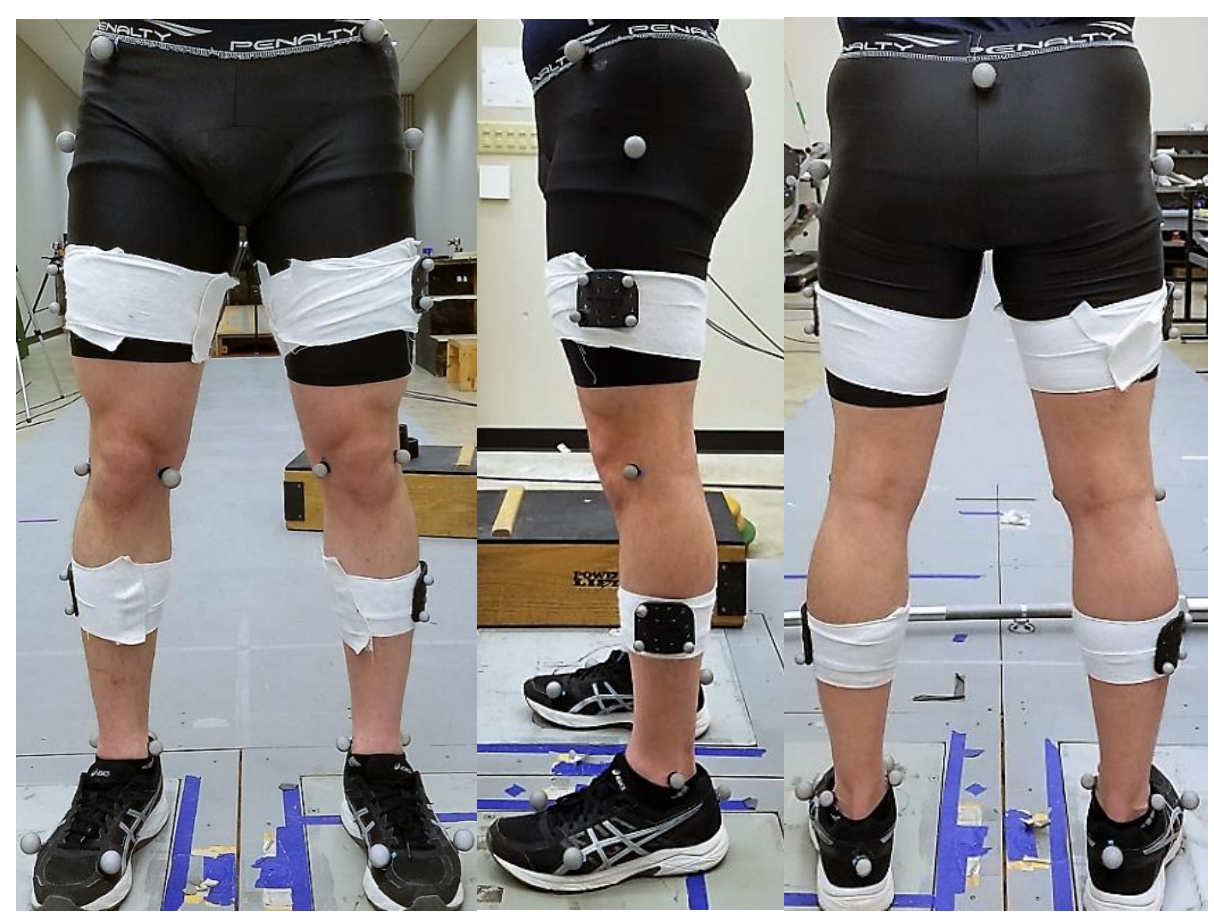

Figure 4 


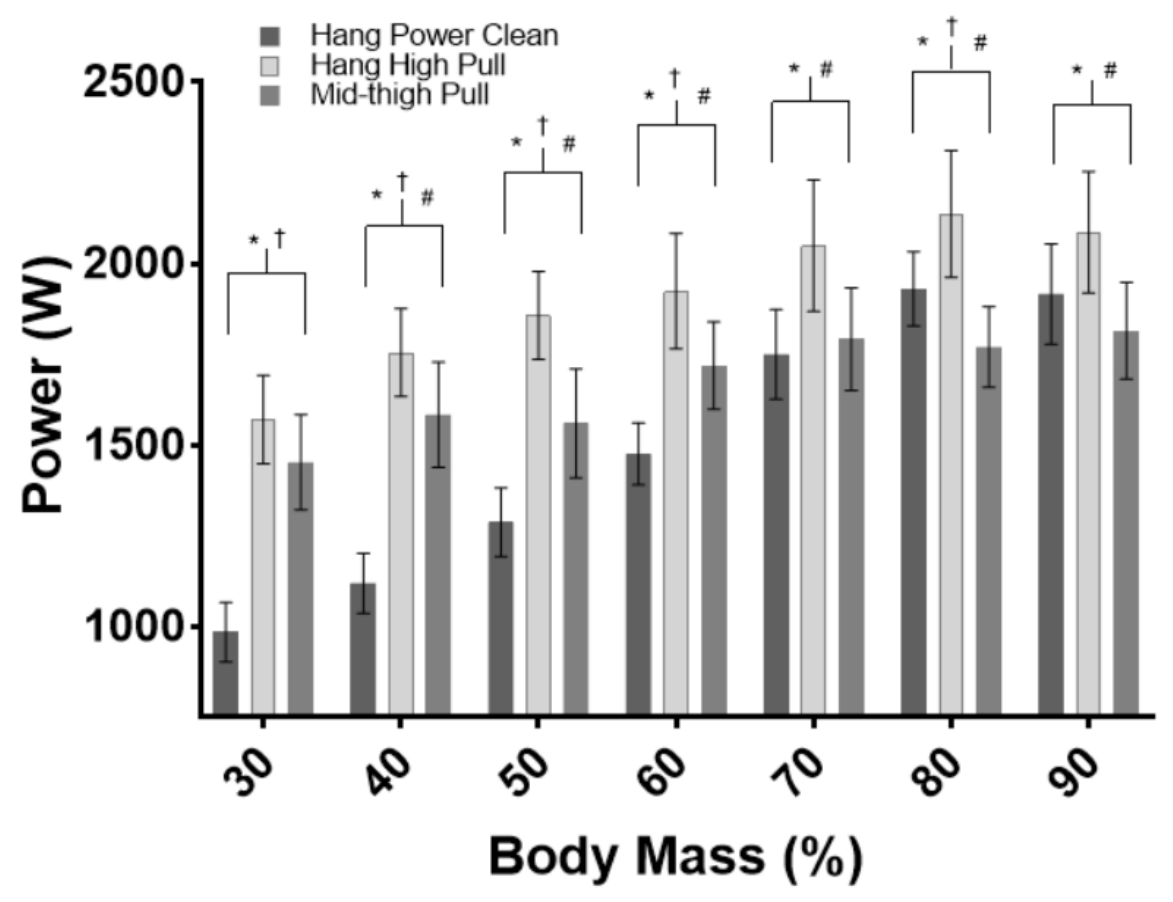

Figure 5 
A)

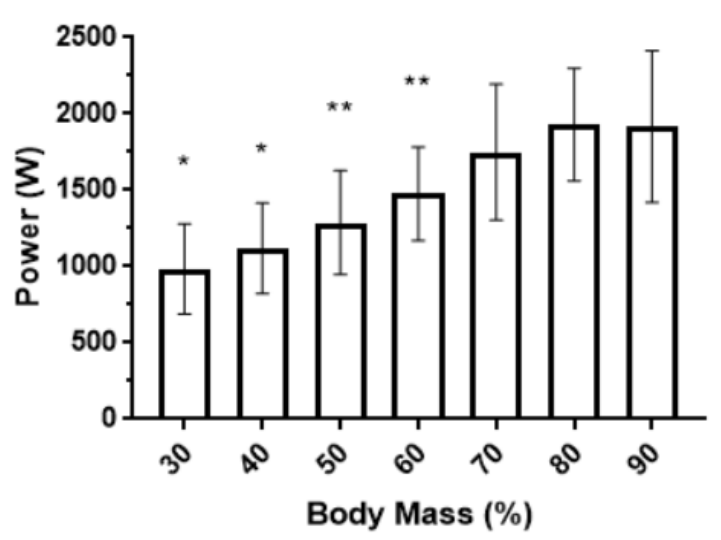

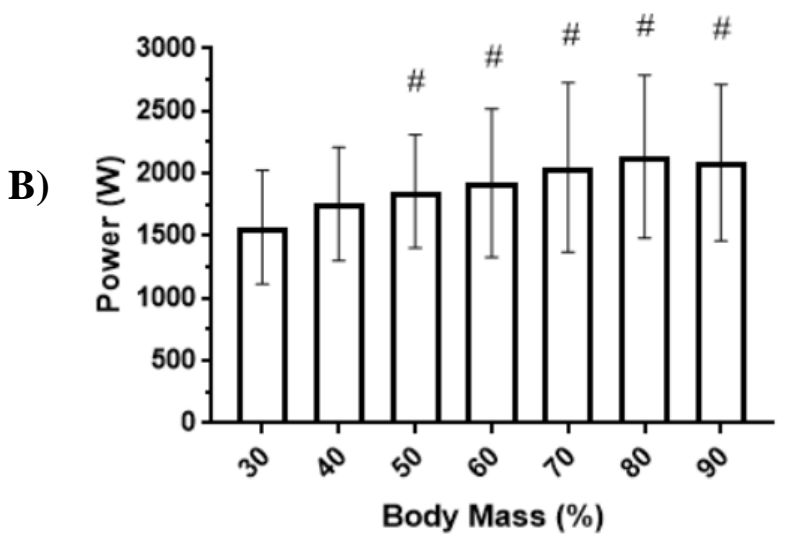

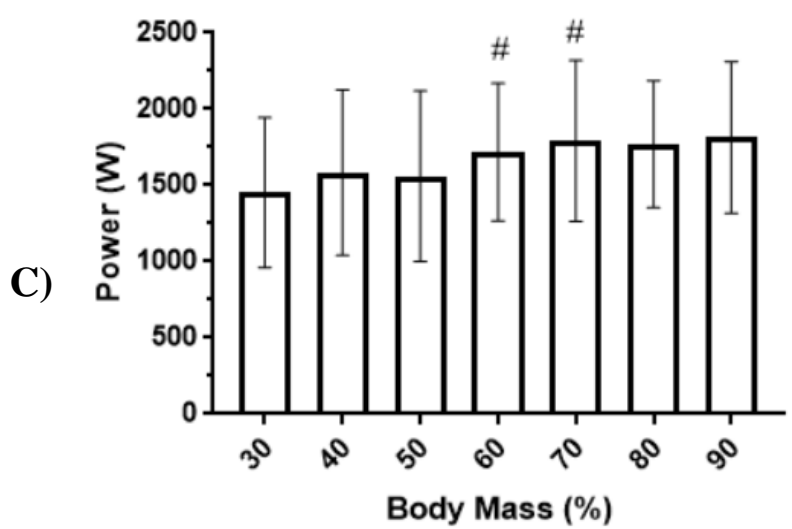

Figure 6 
Table 1. Subjects descriptive characteristics

\begin{tabular}{ll}
\hline Variable & Mean \pm SD \\
\hline Age $(\mathrm{y})$ & $21.8 \pm 1.9$ \\
$\mathrm{BM}(\mathrm{kg})^{*}$ & $83.2 \pm 9.0$ \\
Height $(\mathrm{cm})$ & $175.4 \pm 6.0$ \\
1RM HPC $(\mathrm{kg}) * *$ & $93.0 \pm 12.7$ \\
1RM to BM ratio & $1.12 \pm 0.13$ \\
\hline
\end{tabular}

$* \mathrm{BM}=$ body mass

$* * 1 \mathrm{RM}$ HPC $=1$ repetition maximum hang power clean 
Table 2. Peak power based on body mass percentages for the Hang Power Clean (HPC), Hang High Pull (HHP), and Mid-thigh Clean Pull (MTP).

\begin{tabular}{|c|c|c|c|c|c|c|c|}
\hline \multirow[b]{2}{*}{ Variable } & \multicolumn{7}{|c|}{ Percentage of Body Mass } \\
\hline & $30 \%$ & $40 \%$ & $50 \%$ & $60 \%$ & $70 \%$ & $80 \%$ & $90 \%$ \\
\hline $\mathrm{HPC}(\mathrm{W})$ & $984.58 \pm 82.12 *$ & $1119.31 \pm 82.41^{*}$ & $1287.46 \pm 94.45 * *$ & $1475.86 \pm 85.17 * *$ & $1749.68 \pm 123.56$ & $1931.15 \pm 102.28$ & $1916.20 \pm 137.95$ \\
\hline $\mathrm{HHP}(\mathrm{W})$ & $1570.61 \pm 121.97$ & $1755.07 \pm 120.99$ & $1857.83 \pm 121.31 \#$ & $1924.00 \pm 159.28 \#$ & $2049.40 \pm 181.08 \#$ & $2137.03 \pm 174.36 \#$ & $2086.24 \pm 167.68 \#$ \\
\hline $\operatorname{MTP}(\mathrm{W})$ & $1453.16 \pm 131.45$ & $1583.50 \pm 145.06$ & $1560.02 \pm 149.64$ & $1718.89 \pm 120.65 \#$ & $1791.88 \pm 141.32 \#$ & $1770.41 \pm 111.28$ & $1814.81 \pm 132.96$ \\
\hline
\end{tabular}

* Statistically different than $60,70,80$, and $90 \%(\mathrm{p} \leq 0.003)$

** Statistically different than 80 and $90 \%(\mathrm{p} \leq 0.02)$

\# Statistically different than $30 \%(\mathrm{p} \leq 0.05)$ 